\title{
EXTENDED COST BENEFIT ANALYSIS OF A BIOGAS GENERATION PLANT
}

\author{
K G S P Karunarathna and U A D P Gunawardena \\ Department of Forestry and Environmental Science, \\ University of Sri Jayewardenepura
}

Solid waste is a growing problem in Sri Lanka in the absence of proper management measures. Development and implementation of a National strategy for municipal solid waste management is essential in order to reduce environmental, social and the economic problems associated with the present disposal practices. Such strategies however, need to be subjected to proper economic analysis in order to arrive at informed decisions. This paper presents an extended cost benefit analysis of a biogas generation plant that uses municipal solid waste as the raw material.

To dispose vegetable market garbage available in Wattala, Kandana and Ja-ela areas a 640 Mt capacity biogas/ bio fertilizer project has been housed at Muthurajawela (along Hamilton canal, Elakanda), by the National Engineering Research \& Development Center of Sri Lanka (NERDC) which uses Dry Batch Anaerobic Digester Technology. Among the other biological treatment options, anaerobic digestion is the most cost effective, due to the high-energy recovery linked to the process and its limited environmental impacts.

Economic analysis has been carried out to identify environmental costs and benefits associated with the above project. Several environmental valuation methods have been applied to value the identified costs and benefits. The main benefit of reduction of municipal solid waste has been estimated by contingent valuation method using samples from Wattala-Mabola, Ja-ela, and Peliyagoda local authority areas. Another benefit is the reduction of green house has emission due to the reduction of open dumping. Green house gas (methane) emission from solid waste was estimated through Sholl Canion model and valued using avoided global damage cost approach. Benefits of biogas as energy and organic fertilizers and employment benefits were estimated by market based approaches.

The project is viable from economy and environment point of view with net present value of Rs 142 million for a 20 -year period with $10 \%$ discount rate. This analysis provides a justification for undertaking solid waste management strategies in a technologically, environmentally and economically viable manner.

Proceedings of the Ninth Annual Forestry and Environment Symposium 2003 of the Department of Forestry and Environmental Science, University of Sri Jayewardenepura, Sri Lanka 